\title{
Decreased expression of the interleukin 2 receptor on CD8 recipient lymphocytes in intestinal grafts rendered tolerant by liver transplantation in rats
}

\author{
S Sarnacki, H Nakai, D Calise, T Azuma, N Brousse, Y Révillon, N Cerf-Bensussan
}

\begin{abstract}
Background-In a previous study, it was shown that a spontaneously tolerated DA (RT1a) liver allograft in a PVG (RT1c) recipient was able to induce tolerance of a DA small bowel graft performed 17 days later in spite of infiltration of the intestinal grafts by mononuclear cells.

Aims-To compare the phenotype of graft infiltrating cells in rejecting and tolerated small bowel grafts in order to elucidate the mechanism(s) which block the graft infiltrating cells from mediating rejection.

Methods-Multiparameter immunofluorescence was used to compare the phenotype and state of activation of donor and recipient cells isolated from intestinal grafts rejected or tolerated after liver transplantation.

Results-Three differences were found. Firstly, there was a more rapid replacement of lamina propria (LP) cells by recipient lymphocytes in tolerated than in rejected grafts. Secondly, the proportion of LP recipient CD8 $\alpha \beta+1 y m p h o c y t e s$ bearing the high affinity receptor for interleukin 2 was significantly less in tolerated grafts $(1.1 \%$, range $0-2 \%)$ than in rejected grafts $(21.3 \%$, range $9-26 \%)$. Finally, tolerated grafts contained significantly less NK lymphocytes (NKR-P1+) and macrophages than rejected intestinal allografts.

Conclusions-These observations make it possible to delineate clear cut differences in the phenotype of cells infiltrating rejecting versus tolerated grafts. Furthermore, the data suggest that liver transplantation induces tolerance of intestinal grafts by hampering the activation of recipient $T c R \alpha \beta+C D 8 \alpha \beta+T$ cells and subsequently the recruitment of nonspecific effector cells.

(Gut 1998;43:849-855)
\end{abstract}

Keywords: liver transplantation; small bowel transplantation; tolerance; intestinal T lymphocytes; interleukin 2 receptor; rat

In 1965, Garnier et al reported that liver grafts transplanted between outbred pigs survived spontaneously. ${ }^{1}$ Acceptance of liver allografts was then reported by Calne et al and found to be associated with the development of a state of donor specific unresponsiveness towards simultaneous heart or kidney grafts. ${ }^{2}$ Rejection of skin grafts, on the other hand, could be delayed but not prevented, even when performed two weeks after a successful liver transplant. ${ }^{2}$ These findings were further investigated in the rat model. Kamada showed that PVG (RT1c) rats grafted orthotopically with a DA (RT1a) liver became tolerant to simultaneous DA heart and kidney grafts or to a subsequent DA skin graft. ${ }^{3}$ Finally, in the same rat strain combination, we have shown that liver transplantation induced the indefinite survival of a small bowel graft performed 17 days after the liver graft. ${ }^{4}$ The protective effect of the liver against allograft rejection is strongly suggested but less clearly shown in humans ${ }^{5-8}$ and might be particularly interesting in the case of small bowel transplantation. Indeed a combined liver and small bowel transplantation is indicated in $60 \%$ of cases because of the liver injury induced by long term parenteral nutrition. A better understanding of the mechanism by which the liver graft can induce tolerance of small bowel grafts should be useful to guide immunosuppressive regimens and to improve follow up of patients with combined liver and small bowel transplants.

Although several studies have investigated the problem, the mechanism underlying liver induced tolerance to donor alloantigens remain elusive. It is unrelated to changes in Th1/Th2 subsets. ${ }^{9} 10$ The tolerogenic effect of a microchimerism resulting from the migration of a small number of liver derived donor cells into recipient lymphoid organs was hypothesised but not proved. ${ }^{11-14}$ Clonal deletion of donor specific alloreactive cytotoxic $\mathrm{T}$ cells and a potential role of soluble MHC class I antigens was suggested by Kamada. ${ }^{3}$ A recent study showing that in vitro, soluble MHC class I antigens induced the apoptosis of alloreactive cytotoxic $\mathrm{T}$ cells, provided a rationale for this hypothesis. ${ }^{15}$ Using liver grafts bearing the $\mathrm{Mls}_{\mathrm{f}}$ superantigens, Dahmen et al were however unable to confirm this hypothesis. ${ }^{16}$

In our model of combined liver and small bowel transplantation, we observed that tolerance was obtained in spite of a striking mononuclear cell infiltration of the lamina propria in the intestinal graft. This infiltration was transitory, as by day 150 , the intestinal allografts had recovered a nearly normal histological appearance. ${ }^{4}$ In order to define criteria useful to distinguish the infiltrate in tolerant and rejecting grafts and thereby to obtain an insight into the mechanism(s) which blocked graft infiltrating cells from rejection, we have now used multiparameter immunofluorescence analysis to investigate the phenotype and state 
of activation of donor and recipient cells isolated from intestinal allografts.

\section{Materials and methods}

ANIMALS

Adult DA (RT1a) and PVG (RT1c) rats, 7-9 weeks old, were used as donors and recipients respectively. Animals were purchased from CNRS (Orléans, La Source, France) and Harlan Olac (Bicester, UK) and raised under conventional conditions. All animals were maintained under standard conditions and received water and rodent chow ad libitum. All procedures involving rats were conducted according to the guidelines of the National Institute of Health's Guide for the Care and Use of Laboratory Animals (Bethesda, Maryland, USA).

HEPATIC TRANSPLANTATION

Orthotopic whole liver transplantation was performed using the cuff technique as previously described ${ }^{17}$ with a modification for the revascularisation of the hepatic artery. ${ }^{18}$ Briefly, the suture for the arterial anastomosis was inserted $2 \mathrm{~mm}$ from the end of the donor receiving vessel and pulled through the open end. A small superficial tangential "bite" of the host artery was taken one wall thickness from the cut end and the suture returned into the donor receiving vessel, emerging as close as possible to the first suture entry, thus resulting in invagination of the host artery into the donor vessel. The anastomosis was secured by a superficial suture placed in the adventitia $180^{\circ}$ opposite to the first suture. The recipient anhepatic phase was 17 (1) minutes and the total cold ischaemia time was 75 (8) minutes.

INTESTINAL TRANSPLANTATION

Heterotopic auxiliary small bowel transplantation was performed by the method described by Monchik and Russell. ${ }^{19}$ Briefly, a $15 \mathrm{~cm}$ long proximal small bowel graft was dissected free from $1 \mathrm{~cm}$ beyond the ligament of Treitz. The donor's superior mesenteric artery and portal vein were anastomosed to the recipient aorta and inferior vena cava, respectively, in an end to side fashion using $10 / 0$ and $11 / 0$ nylon sutures. Both graft ends were brought out as enterostomies. All surgical procedures were performed aseptically under ether anaesthesia. The mean (SD) cold ischaemia time of the grafts was 130 (10) minutes. The mean aorta and infrahepatic vena cava clamping time was 60 (5) minutes. Animals that died within two days of transplantation were excluded from further analyses.

\section{EXPERIMENTAL DESIGN}

DA small bowel grafts were transplanted either into naive PVG rats or into PVG rats which had received a DA liver graft 17 days before small bowel transplantation. This two step combined liver/small bowel transplantation leads to indefinite liver and small bowel graft survival (more than 150 days) whereas, in the same donor/recipient strain combination, small bowel grafted alone is consistently rejected on day 8 (1). ${ }^{40}$ Syngeneic DA-DA and PVG-PVG small bowel grafts were also studied. Prelimi- nary studies showed no significant difference in the phenotype of cells isolated from lamina propria of PVG-PVG or DA-DA syngeneic grafts except for the proportion of NKR-P1+ natural killer $(\mathrm{NK})$ cells, which was higher in DA-DA syngeneic grafts than in PVG-PVG grafts $(9 \%$ versus $1.5 \%)$. Therefore in subsequent studies, syngeneic PVG-PVG grafts were used as controls, except for the study of NK cells where comparison was performed with both DA-DA and PVG-PVG grafts.

PREPARATION OF GRAFT INFILTRATING CELLS Recipient rats were sacrificed on days $2,5,6$, and 7 in the group with rejecting small bowel grafts, on days 2, 5, and 45 after intestinal transplantation in the group with tolerated small bowel grafts following liver transplantation, and on day 5 in the group with syngeneic small bowel grafts. In each recipient, cells were isolated from lamina propria (LP) and mesenteric lymph nodes (MLN).

Single cell suspensions were prepared from MLN in RPMI-1640 medium (Gibco, Grand Island, New York, USA) supplemented with $10 \%$ newborn calf serum (Gibco). Briefly, specimens were pressed through a wire mesh and cell suspensions were spun on Ficoll-Hypaque (Pharmacia, Saint-Quentinen-Yvelines, France) at $1800 \mathrm{~g}$ for 15 minutes to eliminate dead cells.

LP lymphocytes were isolated according to a previously described procedure. ${ }^{21}$ After removal of PP, fat, and mesentery, the grafts were flushed with phosphate buffered saline (PBS), opened longitudinally, and cut into small pieces. Mucus was further removed by gentle rubbing and the mucosa was scraped. The fragments were stirred in 199 medium (Gibco) supplemented with $20 \%$ newborn calf serum and $1 \mathrm{mM}$ dithioerythreitol (Sigma Chemical Co., St Louis, Missouri, USA) for 15 minutes to dissolve mucus, washed twice with PBS, and resuspended in PBS supplemented with $0.1 \%$ glucose and $0.78 \mathrm{mM}$ EDTA (Bioprobe Systems, Montreuil-sous-Bois, France) and then agitated in a $37^{\circ} \mathrm{C}$ water bath to remove epithelial cells and intraepithelial lymphocytes; the latter procedure was repeated three times. The remaining fragments were incubated with RPMI at $37^{\circ} \mathrm{C}$ for five minutes, washed twice with PBS, and then stirred in RPMI supplemented with $10 \%$ fetal calf serum (Gibco) and $90 \mathrm{U} / \mathrm{ml}$ collagenase (type C-2139, Sigma) for 60 minutes. Fragments were then disrupted with a syringe. After sedimentation to eliminate debris, the supernatant of collagenase treated fragments was purified by Ficoll gradient (NycoPrep 1.077 Animal, Nycomed Pharma AS, Oslo, Norway) to remove dead cells. Preparation of LP cells contained less than $0.5 \%$ epithelial cells.

\section{FLOW CYTOMETRY}

Mouse monoclonal antibodies against rat CD4 (W3/25), CD8 $\alpha$ (MRC OX8), CD8 $\beta$ (341), TCR $\alpha \beta$ (R 73), IL2-R p55 $\alpha$ chain (MRC OX-39), NKR-P1 antigen (specific for natural killer cells) (3.2.3), and PVG MHC class I (MRC OX-27) were obtained from Serotec 

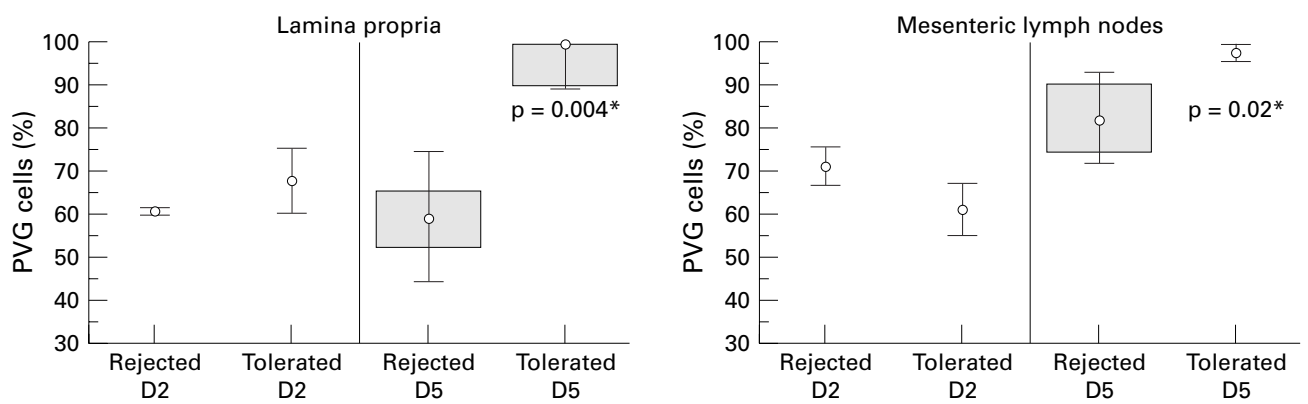

Figure 1 Comparison of the proportions (medians and ranges) of PVG recipient cells in LP and MLN of tolerated and rejected intestinal grafts on day 5. Three and three to seven allografts were analysed in each group on days 2 and 5 respectively. ${ }^{*} p<0.05$ when compared with rejected grafts on day 5.

(Realef, Paris, France). All were directly coupled to fluorescein or phycoerythrein except OX-27 which was biotinylated in our laboratory according to standard procedures. Cells $\left(3 \times 10^{5}\right.$ in $\left.50 \mu \mathrm{l}\right)$ were incubated with saturating concentrations of several monoclonal antibodies (diluted in PBS supplemented with $1 \%$ bovine serum albumin (Sigma) and $0.01 \%$ sodium azide) for $20 \mathrm{~min}-$ utes at $4^{\circ} \mathrm{C}$, washed twice, and resuspended in the same medium. For negative controls, cells were first incubated with isotype matched irrelevant mouse antihuman monoclonal antibodies. Biotinylated OX-27 was revealed by a second incubation with $30 \mu \mathrm{l}$ of a $1 / 200$ dilution of streptavidin-Tricolor (Caltag Laboratories, San Francisco, California, USA). Cells were analysed on an FACScan flow cytometer (Becton Dickinson) using LYSIS II software (Becton Dickinson). Electronic gates were set using side (SSC) and forward (FSC) scatter parameters in order to analyse mononuclear cells and exclude granulocytes and epithelial cells.

HISTOLOGICAL AND IMMUNOHISTOCHEMICAL STUDIES

Tissue samples were fixed in $4 \%$ formaldehyde or snap frozen in liquid nitrogen for histological and immunohistochemical studies respectively. Cryostat tissue sections of small bowel grafts were stained with monoclonal antibodies W3/25, MRC OX-8, 3.4.1, R.73, MRC OX-39 (see above), ED2 (against tissue macrophages), F17-2 (against DA MHC class II) and MRC OX-6 (against an MHC class II monomorphic antigen) (Serotec). Labelling was performed using an indirect immunoperoxidase technique previously described ${ }^{22}$ except that the second antibody was a biotinylated rat antimouse IgG (Jackson ImmunoResearch Laboratories Inc., West Grove, Pennsylvania, USA).

\section{STATISTICAL ANALYSIS}

Data were analysed as non-parametric independent samples by the Mann-Whitney U test using the Statistica version 4.0 (Statsoft, Inc.) software. The level of significance was set at $\mathrm{p}<0.05$. In the text, the percentages of positive cells for each studied marker are expressed as medians. In some cases, the range is indicated in parentheses.

\section{Results}

MIGRATION OF CELLS OF RECIPIENT ORIGIN

Figure 1 shows the appearance of lymphocytes of recipient origin in MLN and LP of rejecting and tolerated grafts. On day 2 , in rejecting as well as in tolerated grafts, $60-70 \%$ of LP and MLN lymphocytes were already of recipient origin. However, on day 5, the proportion of lymphocytes of recipient origin was significantly higher in tolerated than in rejected grafts. The difference was even more pronounced in the lamina propria $(p=0.004)$ than in MLN ( $\mathrm{p}=0.02)$. On day 45, the proportion of lymphocytes of recipient origin was over $95 \%$ in the LP of tolerated grafts (data not shown).

PROPORTION OF TCR $\alpha \beta+$ AND CD $8 \alpha \beta+\mathrm{T}$ LYMPHOCYTES OF RECIPIENT ORIGIN IN LP In syngeneic PVG grafts on day 5, approximately $55 \%$ of isolated lymphocytes were $\mathrm{TcR} \alpha \beta+, 45 \% \mathrm{CD} 4+$, and only $5 \% \mathrm{CD} 8 \alpha \beta+$ (fig 2). In rejecting grafts, on day 5, the proportion of $\mathrm{TcR} \alpha \beta+$ cells among recipient lymphocytes was $60 \%$ with a proportion of CD $8 \alpha \beta+$ cells that increased significantly to $30 \%(p=0.049)$. As the yield of cells extracted from LP was not significantly different between rejecting and syngeneic grafts (median $8.8 \times 10^{6}$, range $4.6-13 \times 10^{6}$ versus $3.9 \times 10^{6}$, $\left.2.8-7.4 \times 10^{6} ; \mathrm{p}=0.08\right)$, this shows an increase in the absolute number of CD $8 \alpha \beta+$ cells. The proportion and the absolute number of PVG TcR $\alpha \beta+$ cells tended to increase $(p=0.56)$ and that of PVG CD $4+$ cells to decrease $(p=0.12)$ when compared with syngeneic grafts, although not significantly.

In tolerated grafts, the proportions of recipient TcR $\alpha \beta+$ and CD $8 \alpha \beta+$ lymphocytes, $79 \%$ and $45 \%$ respectively on day 5 , were significantly increased when compared with syngeneic grafts $(p=0.025$ and $p=0.033)$. This increase was at least as important as that observed in rejecting grafts (fig 2). As in rejecting grafts, this increased proportion reflected a significant increase in the absolute number of TCR $\alpha \beta+$ and CD $8 \alpha \beta+$ lymphocytes. Indeed, the yield of extracted cells in these tolerated grafts was highly variable (median $18 \times 10^{6}$, range $4.9-26.3 \times 10^{6}$ ) but comparable to that observed in syngeneic and rejecting grafts $(\mathrm{p}=0.10$ and $\mathrm{p}=0.22)$. On day 45 , the proportion and the absolute number of PVG 

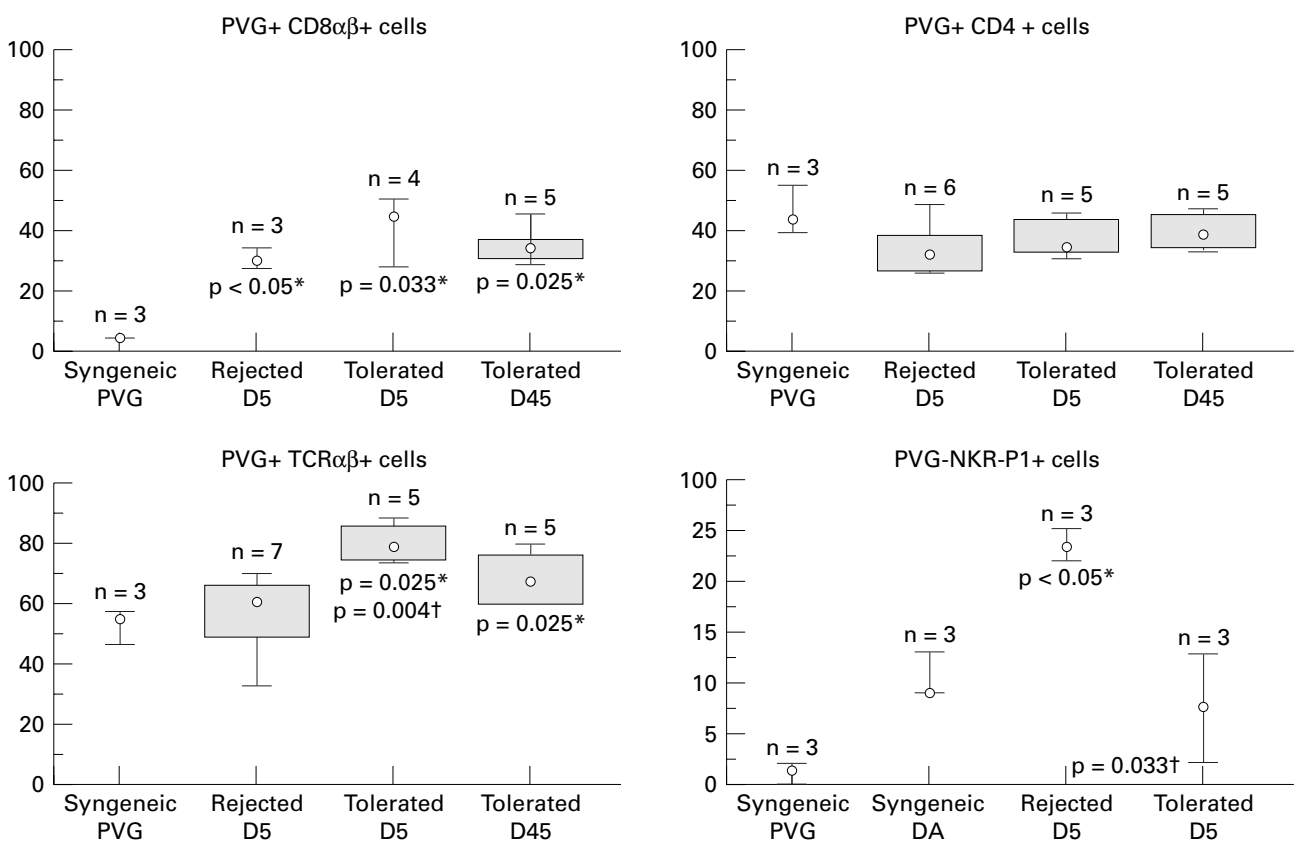

Figure 2 Comparison of the phenotype of recipient lymphocytes in rejected and tolerated intestinal grafts. Each plot shows the median and the range of percentages of double positive cells. The number of animals analysed for each marker is indicated. ${ }^{\star} p<0.05$ when compared with $P V G$ syngeneic grafts on day $5 ; t p<0.05$ when compared with rejected grafts on day 5.

CD8 $\alpha \beta+$ cells isolated from LP remained very high $(36 \%)$, with a comparable yield of LP cells (median $5.3 \times 10^{6}$, range $4-21.5 \times 10^{6} ; \mathrm{p}=0.18$ ). These findings were consistent with immunohistochemistry on frozen tissue sections which showed a notable infiltration of $\mathrm{TcR} \alpha \beta+$ and CD $8 \alpha \beta+$ lymphocytes in the LP of tolerated grafts between day 3 and day 70 following small bowel transplantation. However, in contrast to rejecting grafts, this $\mathrm{T}$ cell infiltration never extended into the muscular layer or serosa and was associated with minor and scattered crypt lesions without any modification of the villous height (not shown). ${ }^{23}$

\section{EXPRESSION OF CD25 ON RECIPIENT LP T LYMPHOCYTES}

The state of activation of the various subsets of lymphocytes infiltrating rejecting and tolerated intestinal grafts was analysed by studying their expression of CD25 (IL-2R) (see table 1). Multiparameter immunofluorescence was used

Table 1 Expression of CD25 on intestinal graft infiltrating $T$ cells of recipient origin on day $5 t$

\begin{tabular}{llll}
\hline & Syngeneic grafts $\neq$ & $\begin{array}{l}\text { Rejected grafts } \\
(59 \%, 44-74) \neq\end{array}$ & $\begin{array}{l}\text { Tolerated grafts } \\
(99 \%, 89-99) \neq\end{array}$ \\
\hline TCR $\alpha \beta+\mathrm{CD} 25+$ & $22 \%(20-31)$ & $22.2 \%(14-33)$ & $15.5 \%(8-24)$ \\
& $(\mathrm{n}=3)$ & $(\mathrm{n}=7)$ & $(\mathrm{n}=3)$ \\
$\mathrm{CD} 8 \alpha \beta+\mathrm{CD} 25+$ & $2.5 \%(2-2.5)$ & $21.3 \%(9-26)^{\star}$ & $1.1 \%(0-2)^{\star}$ \\
$(\mathrm{n}=3)$ & $(\mathrm{n}=3)$ & $(\mathrm{n}=3)$ \\
$\mathrm{CD} 4+\mathrm{CD} 25+$ & $19 \%(16-28)$ & $18.3 \%(11-28)$ & $10.2 \%(7-20)$ \\
& $(\mathrm{n}=3)$ & $(\mathrm{n}=6)$ & $(\mathrm{n}=3)$ \\
NKR-P1+CD25+ & $0.8 \%(0-5)$ & $5.1 \%(2-6)$ & $0.18 \%(0-0.4)$ \\
& $(\mathrm{n}=3)$ & $(\mathrm{n}=3)$ & $(\mathrm{n}=3)$ \\
PVG+CD25+ & $30 \%(24-36)$ & $29.6 \%(19-42)$ & $11.4 \%(10-24)^{\star}$ \\
& $(\mathrm{n}=3)$ & $(\mathrm{n}=7)$ & $(\mathrm{n}=5)$ \\
\hline
\end{tabular}

†Data are percentage of positive cells among graft infiltrating cells of recipient origin (median, range). $\mathrm{n}=$ number of animals analysed.

$\ddagger$ The percentage of cells of recipient origin (median, range) were determined in rejected and tolerated grafts using the OX-27 biotinylated monoclonal antibody as indicated in methods. In syngeneic grafts cells of donor and recipient origin could not be distinguished and immunofluorescence was performed on total cells. ${ }^{\star} \mathrm{p}<0.05$ (Mann-Whitney U test). to compare CD25 expression according to the phenotype and origin of extracted lymphocytes. PVG/DA chimerism was different in rejecting and tolerated animals (see earlier). In addition the high percentage of CD25+ cells among donor DA cells remaining in both rejecting (72.5\%, range $69.3-93.2 \%)$ and tolerated ( $83 \%$, range $80-86 \%$ ) grafts hampered the analysis of the recipient cells involved in the process of allogeneic rejection.

Whereas the differences in the proportion of recipient TCR $\alpha \beta+$ and CD4+ lymphocytes expressing CD25 cells between syngeneic, rejecting, and tolerated intestinal grafts were not significant, the expression of CD25 varied on recipient CD8 $\alpha \beta+$ lymphocytes in rejecting and tolerated grafts. On day 5, 2.5\% of PVG lymphocytes extracted from syngeneic grafts were CD $8 \alpha \beta+\mathrm{CD} 25+$. This proportion was less than in normal unmodified PVG rats (6.7\%, range $3.5-9.5 ; \mathrm{p}=0.033)$, probably due to the lack of exposure of the heterotopic graft to intraluminal antigens. In rejecting grafts, $21 \%$ of recipient lymphocytes were CD $8 \alpha \beta+\mathrm{CD} 25+$, a proportion significantly higher than in syngeneic grafts $(p<0.05)$. In contrast, in tolerated grafts only $1 \%$ of CD $8 \alpha \beta$ lymphocytes of recipient origin expressed CD25, a proportion significantly less than in rejecting grafts $(\mathrm{p}<0.05)$. This proportion remained low on day 45 as only $4 \%$ (range $1.6-7 \%)$ of recipient cells were CD $8 \alpha \beta+$ CD25+ (data not shown).

STUDY OF MACROPHAGES AND NK CELLS Numbers of natural killer cells in syngeneic, rejecting, and tolerated intestinal grafts were compared on day 5 using the NKRP-1 marker. In rats, NKRP1 is mainly expressed by natural killer cells with a higher expression in DA than in PVG strains. ${ }^{24}$ This antigen can also be 

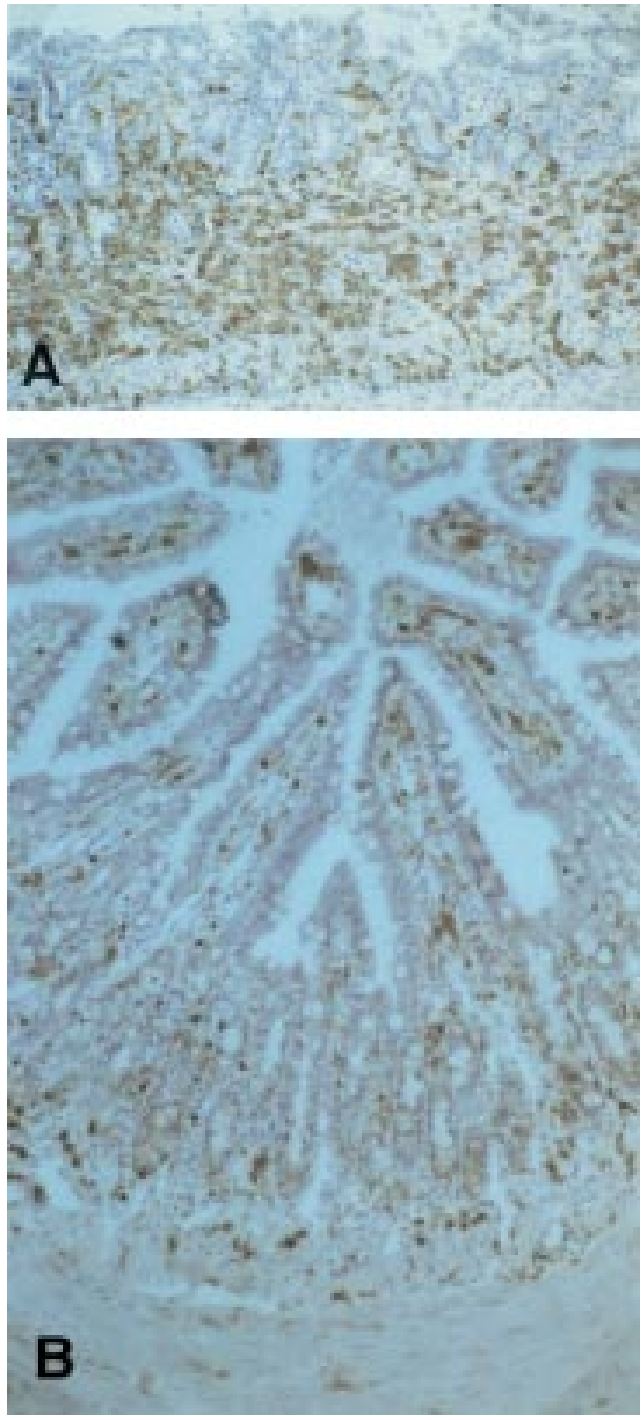

Figure 3 Comparison of ED2+ macrophages in rejected and tolerated grafts. Tissue sections from a rejected intestinal graft on day $9(A)$ and a tolerated graft on day 15 (B) after small bowel transplantation were stained with antitissue macrophage monoclonal antibody ED2, by an indirect immunoperoxidase technique.

expressed by activated neutrophils and by a very small subset of $\mathrm{T}$ cells. ${ }^{25}$ Labelling of granulocytes (rare in rejecting grafts before day 7 , see later) was excluded by setting the analysis gate on lymphocytes. In rejecting grafts, there was a significant increase in the proportion of NKRP-1+ cells of recipient (PVG) origin as compared with syngeneic PVG or DA grafts $(\mathrm{p}<0.05)$ (fig 2).

In contrast, in tolerated grafts on day 5 , the proportion of recipient NKRP1+ lymphocytes was significantly less that in rejecting grafts $(p=0.033)$. It was higher than in PVG syngeneic grafts which contain very few NK cells $(p=0.033)$ but comparable to that observed in DA syngeneic grafts $(\mathrm{p}=0.15)$ (fig 2$)$. Therefore, these results suggest that intestinal graft rejection is associated with a recruitment of NK cells which does not occur or is notably reduced in tolerated grafts.

The presence of macrophages in intestinal grafts was revealed by the ED2 monoclonal antibody on tissues sections using immunohis-
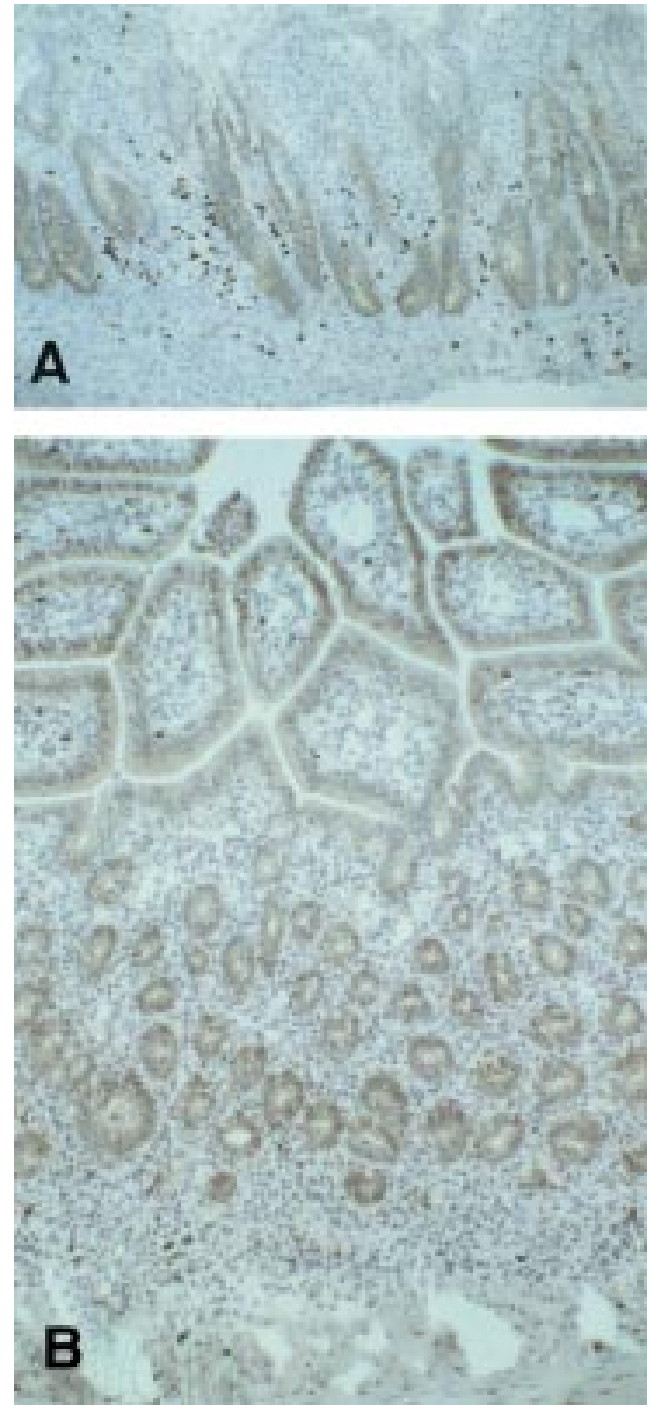

Figure 4 Comparison of donor MHC class II antigens in rejected and tolerated grafts. Tissue sections from a rejected intestinal graft on day $9(A)$ and a tolerated intestinal graft on day $45(B)$ after small bowel transplantation were stained by an indirect immunoperoxidase technique with F17-2, a monoclonal antibody directed against donor DA MHC class II antigens.

tochemistry. On day 3, there was a moderate infiltration of ED2+ cells in the pericryptic region of the LP and in the muscular layers of rejecting grafts. From day 5 and thereafter, this infiltration increased in the muscular layer, around the hyperplasic crypts, and within the axis of the villus in the LP. On day 9, when the process of rejection was almost complete with total villous atrophy and extensive gland destruction, the massive infiltration of the remaining structure of the grafts was essentially made of ED2+ cells and granulocytes (fig 3A). In contrast, in tolerated grafts, no recruitment of ED2+ cells and/or granulocytes cells was observed either on day 5 and 9 after transplantation or at any time during the follow up of tolerated grafts (fig 3B).

Expression of MHC class II antigens by intestinal epithelial cells was studied in tissue sections using OX-6 and F17-32. Rejection was associated with early and persistent expression of MHC class II antigens on crypt epithelium, 
which contrasted with a loss of their normal expression on the villous epithelium after day 5 (fig 4A). In tolerated grafts, there was also an early appearance of MHC class II antigens on crypt epithelium but they remained normally expressed on the villous epithelium. This diffuse expression of MHC class II antigens persisted until day 150 (fig $4 \mathrm{~B}$ ).

\section{Discussion}

This work shows three differences between intestinal grafts rejected or tolerated following liver transplantation. Firstly, there was a more rapid replacement of LP cells by recipient lymphocytes in tolerated than in rejected grafts. Secondly, the LP of both rejected and tolerated intestinal grafts was infiltrated by comparable numbers of recipient TCR $\alpha \beta+\mathrm{CD} 8 \alpha \beta+\mathrm{T}$ cells but the proportion of recipient CD $8 \alpha \beta+$ lymphocytes bearing the high affinity receptor for interleukin 2 (IL-2), CD25, was significantly less in tolerated grafts. Finally, in tolerated grafts, the numbers of NKR-P1+ lymphocytes and of macrophages were notably reduced.

Only a few studies have examined the phenotype of graft infiltrating cells in liver induced tolerance. One study showed a significant increase in the number of B cells in tissue sections of tolerated liver grafts but no change in $\mathrm{T}$ cell subsets or macrophages. ${ }^{26} \mathrm{~A}$ second study failed to identify phenotypical changes specific for rejected or tolerated liver grafts. ${ }^{9}$ Particularly, expression of the high affinity IL-2 receptor (CD25) on tissue sections or by flow cytometry was comparable in both types of liver grafts. Bishop et al studied the phenotype of cells infiltrating cardiac grafts tolerised by liver transplantation using immunohistochemistry on tissue sections. ${ }^{27}$ As in our study, tolerated cardiac grafts were massively infiltrated by $\mathrm{T}$ cells but not by macrophages. In both rejected and tolerated grafts, a large number of cells expressed CD25 although the authors suggested that there may be fewer positive cells in tolerated grafts. ${ }^{27}$ In our study, the use of multiparameter fluorescence analysis on isolated cells allowed us to analyse CD25 expression according to the phenotype and the origin of the cells. CD25 expression was very high on donor cells in both rejected and tolerated intestinal grafts. This high expression of CD25 on donor cells has been previously reported and was ascribed to a graft versus host reaction of donor cells against recipient alloantigens. ${ }^{28}$ On recipient cells, expression of CD25 was not significantly decreased on CD4+ lymphocytes but was strikingly less on recipient CD $8 \alpha \beta+$ lymphocytes isolated from tolerated grafts. This result suggests that the tolerance process specifically affected the recipient $\mathrm{CD} \alpha \beta+\mathrm{T}$ lymphocytes.

On the one hand, activated alloreactive CD $8 \alpha \beta+$ cells might have been deleted in the liver and thus could be undetectable in the intestinal graft. This has been documented in a model of TCR transgenic mice where strong induction of MHC class I antigens on hepatocytes resulted in the deletion of the alloreactive transgenic CD8+ T cells. ${ }^{29}$ Deletion of allore- active $\mathrm{T}$ cells following liver transplantation has been initially suggested by several groups but remains controversial. ${ }^{30}$ Decreased alloreactive cytotoxic $\mathrm{T}$ cell activity has been observed, associated in one recent report with a high level of apoptosis of graft infiltrating cells. ${ }^{31}$ However, a complete deletion of alloreactive cytotoxic $\mathrm{T}$ cell is unlikely as vigorous mixed lymphoid reaction and significant donor specific cytotoxic $\mathrm{T}$ lymphocyte activity could still be generated in long term tolerant recipients. ${ }^{3} 3031$ Furthermore, recent work in mice by Dahmen failed to show deletion of alloreactive $\mathrm{T}$ cells after liver transplantation. ${ }^{16}$

On the other hand, the absence of proliferating recipient $T$ cells in the graft associated lymphoid organs (data not shown) and the lack of CD25 expression on the recipient CD $8 \alpha \beta+$ T cells infiltrating the graft LP suggests a defect in the activation of allogeneic CD $8 \alpha \beta+\mathrm{T}$ lymphocytes. A previous study has emphasised the role of the donor antigen presenting cells present in the graft in the early phase of acute rejection. ${ }^{32}$ Therefore, the accelerated replacement of donor cells observed in the tolerated grafts may hamper the activation of allogeneic $T$ cells. However, expression of CD25 on CD4+ recipient $\mathrm{T}$ cells was comparable in rejecting and tolerated grafts, arguing against this hypothesis. Alternatively, allogeneic CD $8 \alpha \beta+$ lymphocytes might have been rendered unresponsive by the liver transplantation. ${ }^{33}$ This hypothesis is supported by the recent observation in another rat model, that spontaneous acceptance of a liver graft can be prevented by the injection of recombinant IL-2. ${ }^{34}$ Such an anergic state could affect $T$ cell mediated cytotoxicity as well as production of cytokines or chemokines. In our model, the early and persistent expression of MHC class II antigens on the crypt cells in tolerated grafts suggested that the local production of interferon $\gamma$ was not notably affected. ${ }^{35}{ }^{36}$ However, the lack of recruitment of macrophages and $\mathrm{NK}$ cells in tolerated grafts may indicate decreased production of chemokines. ${ }^{37}$

In conclusion, these observations strongly suggest that liver transplantation induces tolerance of intestinal grafts by hampering the activation of recipient allogeneic $\mathrm{TcR} \alpha \beta+$ $\mathrm{CD} 8 \alpha \beta+\mathrm{T}$ cells and subsequently reducing the recruitment of non-specific effector cells. Further work will be necessary to define further how the liver graft interferes with the activation of allogeneic $T$ cells. Such studies will be useful to optimise immunosuppression in patients receiving a combined liver and small bowel transplant.

We thank Ibrahim Astarioglu for helping us to set up liver transplantation, and Marina Cavazzana-Calvo, J Di Santo, Delphine Guy-Grand, and Alain Fischer for helpful discussions. This work was supported by the Association de Recherche contre le Cancer (ARC), the Institut Electricité Santé, and the Fondation de l'Avenir.

1 Garnier H, Clot JP, Bertrand M, et al. Liver transplantation in the pig: surgical approach. Sceances Acad Sci D 1965;260:5621-3.

2 Calne RY, Sells RA, Pena JR, et al. Induction of immunological tolerance by porcine liver allografts. Nature immunological to

3 Kamada N. The immunology of experimental liver transplantation in the rat. Immunology 1985;55:369-89. 
4 Sarnacki S, Révillon Y, Cerf-Bensussan N, et al. Long-term small-bowel graft survival induced by spontaneously toler-
ated liver allograft in inbred rat strains. Transplantation ated liver allog

5 Gonwa TA, Nery JR, Husberg BS, et al. Simultaneous liver and kidney transplantation in man. Transplantation 1988; 46:690-2.

6 Grant D. Current results of intestinal transplantation. Lancet 1996;347:1801-2.

7 Calne R, Davies H. Organ graft tolerance: the liver effect. Lancet 1994;343:67-8.

8 Katznelson S, Cecka JM. The liver neither protects the kidney from rejection nor improves kidney graft survival after combined liver and kidney transplantation from the same donor. Transplantation 1996;61:1403-23.

9 Farges O, Morris PJ, Dallman MJ. Spontaneous acceptance of liver allografts in the rat. Transplantation 1994;57:171-7.

10 Farges O, Morris PJ, Dallman MJ. Spontaneous acceptance of rat liver allografts is associated with an early down regulation of intragraft interleukin-4 messenger RNA expression. Hepatology 1995;21:767-75.

11 Starzl TE, Demetris AJ, Murase N, et al. Cell migration, chimerism, and graft acceptance. Lancet 1992;339:157982.

12 Starzl TE, Demetris AJ, Trucco M, et al. Cell migration and chimerism after whole organ transplantation: the basis of graft acceptance. Hepatology 1993;17:1127-52.

13 Shirwan H, Wang HK, Barwari L, et al. Pretransplant injection of allograft recipients with donor blood or lymphocytes permits allograft tolerance without the presence of persistent donor microchimerism. Transplantation 1996; 61:1382-6.

14 Schlitt HJ, Hundrieser J, Ringe B, et al. Donor-type microchimerism associated with graft rejection eight years after liver transplantation. N Engl F Med 1994;330:646-7.

15 Zavazava N, Krönke M. Soluble class I molecules induce apoptosis in alloreactive cytotoxic T lymphocytes. Nat Med 1996;2:1005-10.

16 Dahmen U, Qian S, Rao AS, et al. Split tolerance induced by orthotopic liver transplantation in mice. Transplantation orthotopic liver

17 Kamada N, Calne RY. Orthotopic liver transplantation in the rat: technique using cuff for portal anastomosis and biliary drainage. Transplantation 1979;28:28-47.

18 Duminy FJ. A new microvascular "sleeve" anastomosis. $\mathcal{f}$ Surg Res 1989;46:189-94

19 Monchik GJ, Russell PS. Transplantation of small bowel in the rat: technical and immunological considerations. Surgery 1971;70:693-702.

20 Lear PA, Cunningham AJ, Crane PW, et al. Lymphocyte migration pattern in small bowel transplant. Transplant Proc 1989;21:2881-2.

21 Davies MDJ, Parrott DMV. Preparation and purification of lymphocytes from the epithelium and lamina propria of murine small intestine. Gut 1981;22:481-8.

22 Cerf-Bensussan N, Quaroni A, Kurnick JT, et al. Intraepithelial lymphocytes modulate Ia expression by intestinal epithelial intestinal cells. f Immunol 1984;132:2244-52.
23 Sarnacki S, Cerf-Bensussan N, Révillon Y, et al. Long-term small-bowel graft survival induced by spontaneously tolerated liver allograft in inbred rat strains: study of pathological and immunohistochemical changes. Transplant Proc 1992;24:1210

24 Dissen E, Berg SF, Westgaard IH, et al. Molecular characterization of a gene in the rat homologous to human CD94. Eur F Immunol 1997;27:2080-6.

25 Webster GA, Bowles MJ, Karim S, et al. Activation antigen expression on peripheral blood neutrophils following rat small bowel transplantation. NKR-P1 is a novel antigen preferentially expressed during allograft rejection. Transplantation 1994;58:707-12.

26 Sun J, McCaughan W, Matsumoto Y, et al. Tolerance to rat liver allografts. I. Difference between tolerance and rejection are more marked in the $\mathrm{B}$ cell compared with $\mathrm{T}$ rejection are more marked in the B cell compared with T 57.

27 Bischop GA, Sun J, Johnston B, et al. Comparison of immune changes in rejecting rat cardiac allografts with tolerant cardiac allografts secondary to liver grafts. Transplant Proc 1995;27:2161-2.

28 Webster GA, Wood RFM, Pockley AG. Localized graftversus-host response in the graft mesenteric lymph node after fully allogeneic rat small bowel transplantation. Transplant Proc 1996;28:2449.

29 Bertolino P, Heath WR, Hardy CL, et al. Peripheral deletion of autoreactive CD8+ T cells in transgenic mice expressing $\mathrm{H}-2 \mathrm{~Kb}$ in the liver. Eur f Immunol 1995;25:1932-42.

30 Davies H, Kamada N, Roser BJ. Mechanisms of donorspecific unresponsiveness induced by liver grafting. Transplant Proc 1983;15:831-5.

31 Qian S, Lu L, Fu F, et al. Apoptosis within spontaneously accepted mouse liver allografts. Evidence for deletion of cytotoxic $\mathrm{T}$ cells and implications for tolerance induction. f Immunol 1997;158:4654-61.

32 Braun MY, McCormack A, Webb G, et al. Mediation of acute but not chronic rejection of $\mathrm{MHC}$-incompatible rat kidney grafts by alloreactive CD $4 \mathrm{~T}$ cells activated by the direct pathway of sensitization. Transplantation 1993;55: direct path 82 .

33 Schwartz RH. A cell culture model for T lymphocyte clonal anergy. Science 1990;248:1349-56.

$34 \mathrm{Tu}$ Y, Arima T, Flye MW. Rejection of spontaneously accepted rat liver allografts with recipient interleukin-2 treatment or donor irradiation. Transplantation 1997;63: $177-81$

35 Glimcher LH, Kara CJ. Sequences and factors: a guide to MHC class II transcription. Annu Rev Immunol 1992;10: $13-49$.

36 Steiniger B, Falk P, Lohmüller M, et al. Class II MHC antigens in the rat digestive system. Normal distibution and vivo. Immunology 1989:68:507-13.

37 Fairchild RL, VanBuskirk AM, Kondo T, et al. Expression of chemokine genes during rejection and long-term acceptance of cardiac allografts. Transplantation 1997;63:1807-12. 